\title{
Estudo de caracterização de argilas não plásticas da região de Poços de Caldas, MG
}

\section{(Study of the characterization of non-plastic clays from Poços de Caldas, MG, Brasil)}

\author{
S.C.Maestrelli, C.D.Roveri, A. G. P. Nunes, L.M.Faustino, G. F. Aielo, L. P. A. Pinto, \\ C.Manochio, T.M.L.Cal, F. F. Ribeiro, N.A.Mariano \\ Instituto de Ciência e Tecnologia, Universidade Federal de Alfenas, Campus Avançado de Poços de Caldas, \\ Rod. José Aurélio Vilela 11999 (BR 267, km 533), Cidade Universitária, Poços de Caldas, MG 37715-400 \\ sylma.maestrelli@unifal-mg.edu.br
}

\begin{abstract}
Resumo
Poços de Caldas é um importante centro hidrotermomineral do Brasil, o qual apresenta depósitos de argilas não plásticas para as quais não há registros significativos a respeito da caracterização direcionada destes materiais, o que prejudica estudos de aplicação industrial. Estas argilas não plásticas, não aproveitadas, vêm sendo armazenadas em galpões ou a céu aberto, o que gera um elevado custo para a indústria, além de transformar-se em um passivo ambiental. No presente trabalho realizou-se o estudo químico-mineralógico de seis amostras de argilas de baixa plasticidade, além da caracterização preliminar destas amostras quanto à granulometria, plasticidade e propriedades cerâmicas básicas, visando ampliar os horizontes das investigações destes materiais . Este estudo preliminar mostrou que, de maneira geral, as amostras são compostas por minerais refratários como caulinita e gibbsita, apresentando teores menos significativos de outras fases, como quartzo, vermiculita e illita. Juntamente às análises químicas, estes dados permitiram o agrupamento das matérias-primas em dois grupos em função de sua refratariedade, norteando assim, a caracterização posterior. Dentre as amostras, há material com potencial uso na formulação de massas de porcelanato, além de uma amostra turfosa, cuja aplicação está relacionada à correção de solos.
\end{abstract}

Palavras-chave: argilas não plásticas, caracterização químico mineralógica, Poços de Caldas.

\begin{abstract}
Poços de Caldas is an important "hydro-thermo-mineral" center in Brazil, where non-plastic clays deposits can be found with no significant records about their characterization, impeding the studies of industrial application. These non-plastic clays, not used, have been stored in sheds or open, which creates a high cost to the industry, and become an environmental liability. In the present work, the chemical-mineralogical study of six samples of non-plastic clays was realized, and also the preliminary characterization of these samples about the grain size, plasticity and basic ceramic properties, to expand the horizons of researches about such materials. This preliminary study showed that, overall, the samples are composed of refractory minerals such as kaolinite and gibbsite, with less significant amounts of other phases such as quartz, illite and vermiculite. The chemical analysis permitted the grouping of raw materials into two groups according to their refractory properties, guiding to the subsequent characterization. Among the samples, there is material with potential use in porcelain formulation, and also a peat sample, which implementation is related to soil correction.
\end{abstract}

Keywords: non-plastic clays, chemical-mineralogical characterization, Poços de Caldas.

\section{INTRODUÇÃO}

O setor cerâmico é um importante consumidor de minerais industriais. Os mais diversificados segmentos do ramo cerâmico industrial consomem, por ano, mais de cem milhões de toneladas de rochas e minerais industriais (in natura ou beneficiados), em função de sua aplicação industrial [1]. A fabricação de produtos cerâmicos, especialmente pisos e revestimentos, concentra-se nas regiões sul e sudeste do Brasil, onde são situados os Arranjos Produtivos Locais de maior expressividade, nacional e internacionalmente [2]. A região de Poços de Caldas, MG, se destaca no setor minerário, pelos depósitos e minas de bauxita, além de seu passado histórico como produtora de minério de urânio e por ocorrências de minério de ferro e badeleita, explorados na primeira metade do século XX [3]. As rochas potássicas encontradas na região (nefelina sienitos, tinguaítos, fonólitos e foiaítos) são fonte de matéria-prima para a fabricação de diversos produtos, em função de seu grau de intemperismo. Quando o grau de intemperismo é insipiente, as matériasprimas podem ser utilizadas na fabricação de fertilizantes de liberação lenta, brita e rochas ornamentais. Quando estas rochas se encontram em um estágio de alteração mais acentuado, há a geração de depósitos de argilas não plásticas 
[4]. Trabalhos de prospecção e pesquisa mineral, executados por empresas da região, mostram que algumas matériasprimas encontradas nestes depósitos apresentam potencial para uso na fabricação de refratários. Porém, não há registros científicos significativos a respeito da caracterização direcionada destas matérias-primas não plásticas, o que prejudica estudos de aplicação industrial. Do ponto de vista ambiental, estes materiais, não aproveitados, vêm sendo armazenados em galpões ou a céu aberto, o que gera um elevado custo para a indústria, além de transformar-se em um passivo ambiental [5]. Estas matérias-primas não plásticas são chamadas comumente de argilas, por serem formadas, em grande parte por argilominerais. Quimicamente, os argilominerais são compostos por silicatos hidratados de alumínio, podendo conter ainda, certo teor de elementos alcalinos e alcalino-terrosos [6].

Durante os processos de queima, as argilas sofrem transformações relevantes de caráter físico e químico, envolvendo interações entre os seus constituintes, dos quais se destacam transformações de fases, além de reações de perda de água de constituição, oxidação de matéria orgânica, decomposição de hidróxidos e carbonatos, dentre outras [6, 7]. Estes materiais não apresentam plasticidade, que é a capacidade de moldabilidade ou conformação, de modo a se obter um corpo a verde com características adequadas às subseqüentes etapas de processamento, por apresentar, como fase acessória, grande percentual de quartzo. Deste modo, apresentando baixa plasticidade, em função da presença de quartzo, e ocorrência de diversos álcalis, que por vezes inviabilizam o uso como matéria-prima refratária, estes materiais não são utilizados pelo setor fabril. Neste contexto, este trabalho tem como objetivo fazer a caracterização químico-mineralógica e tecnológica de seis amostras de matérias-primas não plásticas, encontradas na região de
Poços de Caldas- MG, buscando a avaliação preliminar de suas potencialidades para aplicações na indústria cerâmica.

\section{MATERIAIS E MÉTODOS}

Seis amostras distintas de matérias-primas não plásticas, denominadas neste trabalho de argilas, oriundas da região de Poços de Caldas (Fig. 1) foram caracterizadas por ensaios químico-mineralógicos. As amostras foram coletadas em uma frente de lavra na cidade de Poços de Caldas, Bairro Marco

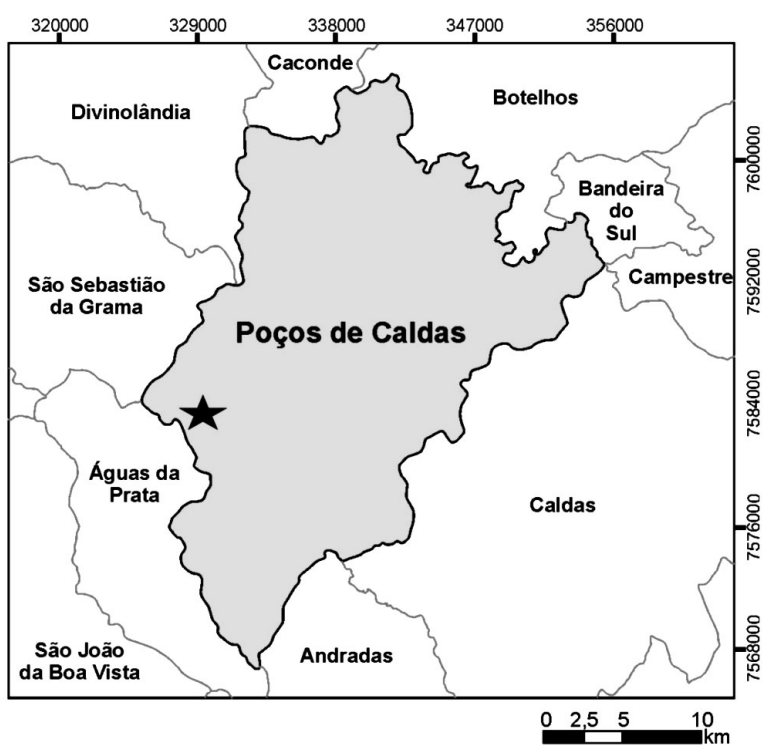

Figura 1: Localização regional do ponto de coleta das amostras estudadas. A extração de argila visitada é representada na figura pelo símbolo de estrela.

[Figure 1: Regional location of the point of collection of samples. The clay quarry is shown in figure by the star.]

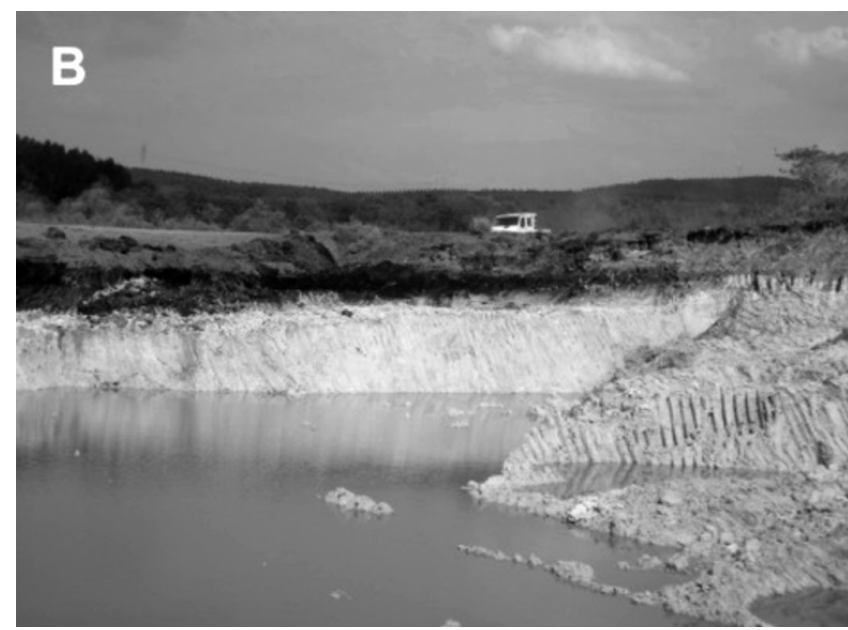

Figura 2: Aspectos gerais da frente de lavra onde as amostras foram coletadas. (A) região onde foram coletadas as amostras AM1 (porção mais clara) e AM6 (porção mais escura). (B) região de coleta das amostras AM2, AM3, AM4 e AM5 (porções claras, amostras diferenciadas via análise química).

[Figure 2: Overview of the front of the quarry where the samples were collected.(A) region where were collected the AM1 (lighter portion) and AM6 (darker portion) samples. (B) region of AM2, AM3, AM4 and AM5 sample collection (lighter portion, differentiated samples for chemical analysis).] 
Divisório, no entorno da Fazenda Chapadão, cujos direitos minerários pertencem a uma empresa da região (Fig. 2).

A análise química foi feita pela técnica de fluorescência de raios $\mathrm{X}$, determinando-se os elementos maiores. A análise granulométrica foi feita em duas etapas. A primeira, pela técnica de peneiramento a seco, com peneiras de abertura (em mm): 4,76, 3,36, 2,38, 1,4, 0,59, 0,21, 0,15, 0,074 e 0,044 ; a segunda etapa foi feita em sedígrafo Sedigraph 5100 Micromeritcs, para determinação das frações finas.

As amostras para a análise mineralógica por difração de raios $\mathrm{X}$ foram desagregadas em almofariz, em água, com uso de pistilo revestido de borracha, para não "fragmentar" as partículas. Os estudos de análise total foram feitos em difratômetro de raios X Siemens D5000 com radiação de Co (1,7893 $)$. A velocidade do goniômetro foi definida com passo igual a $0,05^{\circ}$ e tempo de exposição de $0,8 \mathrm{~s}$ por passo.

As medidas de densidade real foram feitas por picnometria a hélio em picnômetro Micromeritics Accupyc 1330, e a área de superfície específica das amostras (BET), na forma de pó, foi determinada em equipamento Micromeritics Gemini 2370.

O índice de plasticidade foi obtido por meio da diferença entre os valores do limite de liquidez, cujo ensaio foi realizado de acordo com a norma NBR 6459/1984 da ABNT, e os valores do limite de plasticidade de cada amostra, executado segundo a norma NBR 7180/1984 da ABNT.

Para iniciar a caracterização tecnológica destes materiais foi realizada sua desagregação e peneiramento em peneira ABNT de abertura $0,21 \mathrm{~mm}$. As amostras, na forma de pó, após o peneiramento, foram umidificadas e granuladas utilizando um teor de água de $10 \%$. Os corpos de prova, de $6 \mathrm{~cm} \times 2 \mathrm{~cm}$, foram obtidos por prensagem em prensa hidráulica Luxor, a $250 \mathrm{kgf} / \mathrm{cm}^{2}$. Após a conformação foram feitas medidas de densidade a verde, pelo cálculo da média aritmética de 6 corpos de prova para cada argila investigada. Após as queimas a $1000{ }^{\circ} \mathrm{C}$ e $1100{ }^{\circ} \mathrm{C} / 2 \mathrm{~h}$ em forno tipo mufla, foram determinados os valores de perda ao fogo de cada argila, bem como a retração linear de queima.

\section{RESULTADOS E DISCUSSÃO}

A Tabela I indica a análise química das amostras investigadas.

A argila AM1 apresenta maior quantidade de alumina (50\%) e baixo teor de álcalis, o que indica uma refratariedade elevada. Apesar da alta refratariedade, esta amostra possui, entre as argilas estudadas, a mais elevada perda ao fogo, corroborando com a presença de materiais de fácil decomposição a elevadas temperaturas. Trata-se de um material exposto a constante circulação de água, numa pequena bacia terciário-quaternária da região, o que explica o baixo teor de álcalis e a elevada concentração de matéria orgânica. As turfas são materiais argilo-arenosos formados da decomposição de vegetais que crescem emergindo ou sobrenadando na água, sedimentação de areia e limo e argilas oriundas de terrenos à montante juntamente com a vegetação presente nas bordas da região alagada. Este é o contexto observado no ponto de coleta. Em função deste ambiente, para a amostra AM6, a porcentagem de perda ao fogo é alta, aproximadamente $41 \%$, devido à grande quantidade de matéria orgânica e água que se perde durante o aquecimento. As argilas AM3, AM4 e AM5 apresentam quantidades consideráveis de óxidos alcalinos fundendes $\mathrm{K}_{2} \mathrm{O}+\mathrm{Na}_{2} \mathrm{O}$, o que contribui para a formação da fase líquida. Os óxidos alcalinos terrosos $(\mathrm{MgO}$ e $\mathrm{CaO})$ também podem atuar como fundentes durante o processo de queima; tais óxidos reagem com fases amorfas e formam fases cristalinas que são mais estáveis frente a umidade [9]. A elevada presença de óxido de ferro nestas argilas também pode contribuir para a formação de eutéticos de baixo ponto de fusão. As amostras em geral apresentam quantidades variáveis de sílica, o que está relacionado diretamente à menor plasticidade (e retração) das argilas e com o aumento da refratariedade das mesmas. Estas amostras, na extração de argila na qual foram coletadas, ocorrem sobrepostas (AM2 a AM5, numa frente de lavra e AM6 e AM1, em outra), interdigitando-se em alguns pontos. Trata-se de materiais expostos a intempérie,

Tabela I - Análise química das amostras.

[Table I - Chemical analysis of the samples.]

\begin{tabular}{|c|c|c|c|c|c|c|}
\hline$(\%)$ & AM1 & AM2 & AM3 & AM4 & AM 5 & AM6 \\
\hline Perda ao fogo & 26,56 & 15,72 & 12,08 & 19,23 & 14,73 & 41,02 \\
\hline $\mathrm{Al}_{2} \mathrm{O}_{3}$ & 51,78 & 37,18 & 36,18 & 43,92 & 39,02 & 29,89 \\
\hline $\mathrm{SiO}_{2}$ & 14,8 & 40,51 & 43,41 & 30,78 & 39,38 & 24,42 \\
\hline $\mathrm{TiO}_{2}$ & 5,1 & 4,39 & 1,62 & 1,77 & 1,77 & 2,08 \\
\hline $\mathrm{Fe}_{2} \mathrm{O}_{3}$ & 1,41 & 1,87 & 2,69 & 2,28 & 2,19 & 1,11 \\
\hline $\mathrm{CaO}$ & 0,05 & 0,05 & 0,05 & 0,06 & 0,06 & 0,05 \\
\hline $\mathrm{MgO}$ & 0,05 & 0,07 & 0,38 & 0,19 & 0,28 & 0,23 \\
\hline $\mathrm{Na}_{2} \mathrm{O}$ & 0,06 & 0,01 & 0,13 & 0,09 & 0,15 & 0,03 \\
\hline $\mathrm{K}_{2} \mathrm{O}$ & $\mathrm{NE}$ & 0,02 & 3,22 & 1,49 & 2,20 & 0,82 \\
\hline $\mathrm{P}_{2} \mathrm{O}_{5}$ & 0,02 & 0,02 & 0,04 & 0,04 & 0,05 & 0,19 \\
\hline $\mathrm{Cr}_{2} \mathrm{O}_{3}$ & 0,12 & 0,11 & 0,11 & 0,11 & 0,10 & 0,10 \\
\hline
\end{tabular}


Tabela II - Análise granulométrica das amostras.

[Table II - Particle size distribution of the samples.]

\begin{tabular}{ccccccc}
\hline Abertura $(\mathrm{mm})$ & AM1 & AM2 & AM3 & AM4 & AM 5 & AM6 \\
\hline 4,76 & 0,00 & 0,00 & 2,50 & 0,36 & 0,69 & 0,00 \\
3,36 & 0,02 & 0,06 & 0,83 & 1,18 & 0,30 & 0,96 \\
2,38 & 0,19 & 0,12 & 0,55 & 0,55 & 0,46 & 1,82 \\
1,4 & 0,68 & 0,09 & 1,93 & 2,34 & 0,77 & 5,13 \\
0,59 & 0,67 & 0,20 & 2,33 & 2,5 & 1,15 & 11,01 \\
0,21 & 1,78 & 0,94 & 5,38 & 2,53 & 1,96 & 10,72 \\
0,15 & 1,03 & 1,39 & 3,72 & 0,75 & 1,07 & 3,03 \\
0,074 & 1,68 & 2,39 & 7,86 & 1,12 & 1,87 & 4,05 \\
0,044 & 0,76 & 0,56 & 3,56 & 0,62 & 1,34 & 2,12 \\
$<0,044$ & 93,13 & 94,25 & 71,34 & 88,05 & 90,39 & 61,13 \\
\hline
\end{tabular}

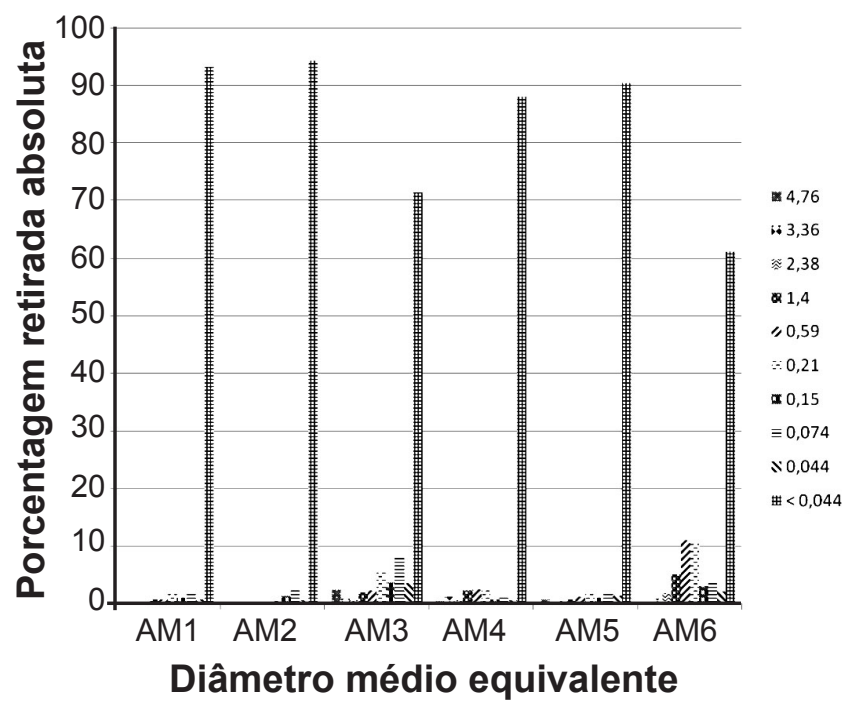

Figura 3: Distribuição granulométrica das amostras.

[Figure 3: Particle size distribution of the samples.]

numa bacia sedimentar terciário-quaternária suspensa, como ocorre em diversos pontos [8]. As amostras são produtos de processo de pedogênese, sendo representadas pelos Horizontes A, B e C. O Horizonte D não é encontrado neste ponto. A Tabela II e Fig. 3 indicam os resultados obtidos a partir do ensaio de distribuição granulométrica efetuada via peneiramento.

O resultado obtido pela análise granulométrica via peneiramento indica que todas as argilas estudadas são bastante finas, o que contribui para maior sinterabilidade durante o processo de queima, devido à maior reatividade das partículas. As argilas AM3 e AM6 apresentam, comparadas às demais, maior fração grossa; entretanto, a presença de álcalis nas mesmas, discutida anteriormente, contribui positivamente para o desenvolvimento de fases líquidas viscosas. A Fig. 4 mostra os difratogramas de raios $\mathrm{X}$ de amostra total obtidos para os materiais estudados. As amostras, de maneira geral, são compostas por minerais refratários como caulinita e gibbsita, apresentando teores menos significativos de outras fases, como quartzo e muscovita. Foram encontradas, em análise preliminar realizada utilizando lupa manual, agregados que podem ser vermiculita, porém trata-se de fragmentos pontuais. A Fig. 5 apresenta os valores de densidade real obtidos para as amostras estudadas. Comparando-se estes resultados com os de análise química anteriormente discutidos, observa-se que os maiores valores de densidade real obtidos devem-se à maior presença de alumina e ferro na forma de óxidos e

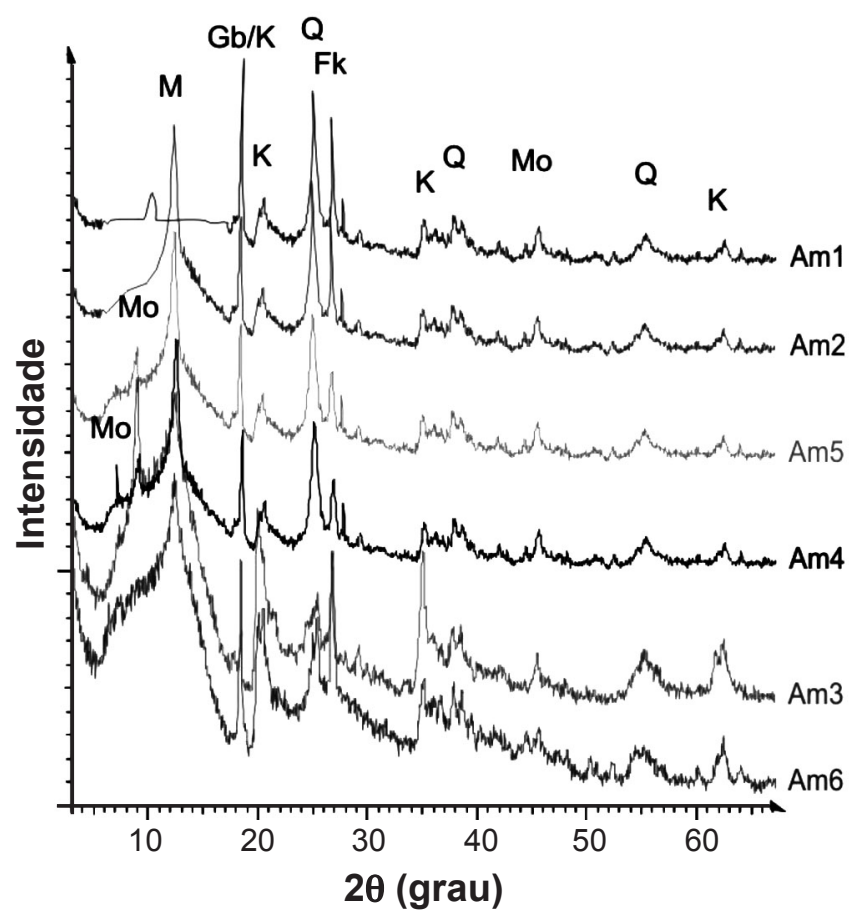

Figura 4: Difratogramas de raios $X$ das amostras AM1 a AM6; as demais siglas referem-se à mineralogia encontrada: Mo (montmorillonita); M (muscovita); K (caulinita); Gb (gibbsita); Q (quartzo); Fk (feldspato potássico).

[Figure 4: X-ray diffraction patterns of the AM1 to AM6 samples: Mo = Montmorillonite $; M=$ Muscovite $; K=$ Kaolinite $; G b=$ Gibbsite; $Q=$ Quartz; Fk(Feldspar).] 
hidróxidos, por exemplo, a goethita.

A Fig. 6 mostra os resultados referentes à área de superfície específica, obtidos pelo método BET. Essa área está relacionada diretamente com a reatividade do pó, assim como a distribuição granulométrica e a forma das partículas; o menor tamanho das partículas (maior área superficial) favorece a redução da temperatura e o tempo necessários na

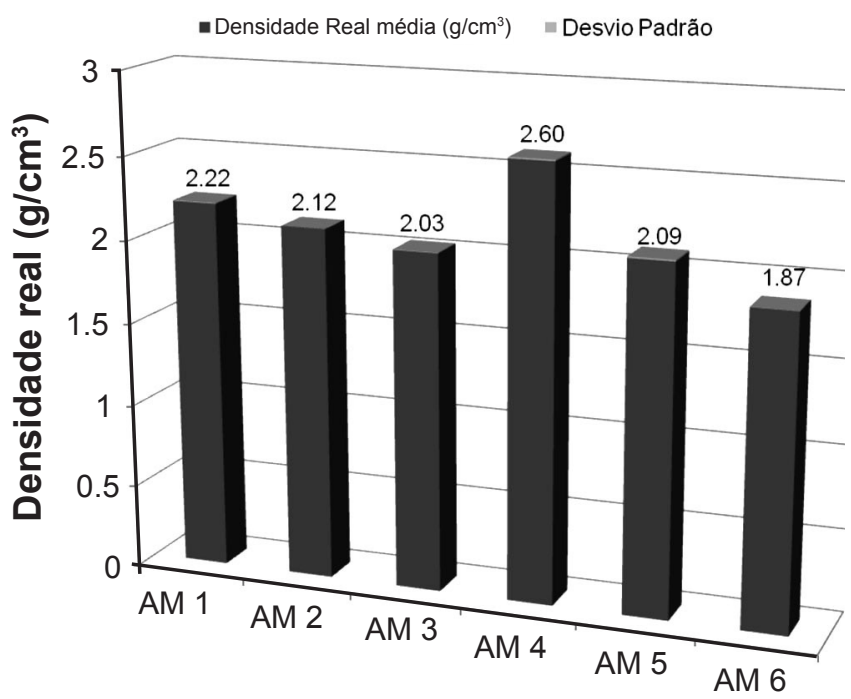

Figura 5: Densidade real das argilas.

[Figure 5: Density of clay minerals.]

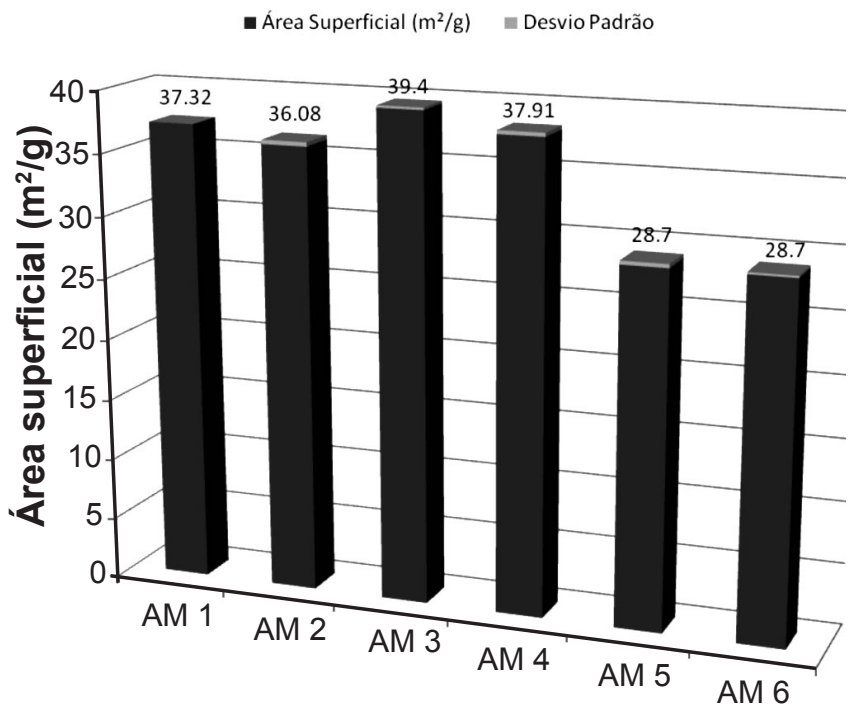

Figura 6: Área de superfície específica das amostras.

[Figure 6: Specific surface area of the samples.]

sinterização do material cerâmico, o que implica diretamente na redução de custos sob o ponto de vista industrial [9]. As argilas AM5 e AM6 apresentaram menores valores de área de superfície específica, ambas menores que $30 \mathrm{~m}^{2} / \mathrm{g}$; as demais amostras apresentaram maior área de superfície específica, acima de $35 \mathrm{~m}^{2} / \mathrm{g}$. Este fato pode ser relacionado à lixiviação sofrida por estes materiais, que representam a porção superior das duas frentes de lavra onde foram coletados os materiais. Com a lixiviação, o particulado maior é extraído do material, reduzindo a área superficial do conjunto.

Na Fig. 7, que representa os resultados da distribuição do tamanho de partículas das amostras investigadas, notase que pela análise granulométrica obtida no sedígrafo, as curvas geradas para as amostras são monomodais. Pela análise destas curvas, verifica-se que a argila AM3 apresenta os menores tamanhos de partícula, já que possui $50 \%$ de sua distribuição $<1 \mu \mathrm{m}$. A amostra AM2 apresenta comportamento semelhante, onde $50 \%$ das partículas têm diâmetro equivalente $<3 \mu \mathrm{m}$. As argilas AM5, AM1 e AM6 apresentaram granulometria mais grossa que as demais, com tamanho médio $\sim 10 \mu \mathrm{m}$.

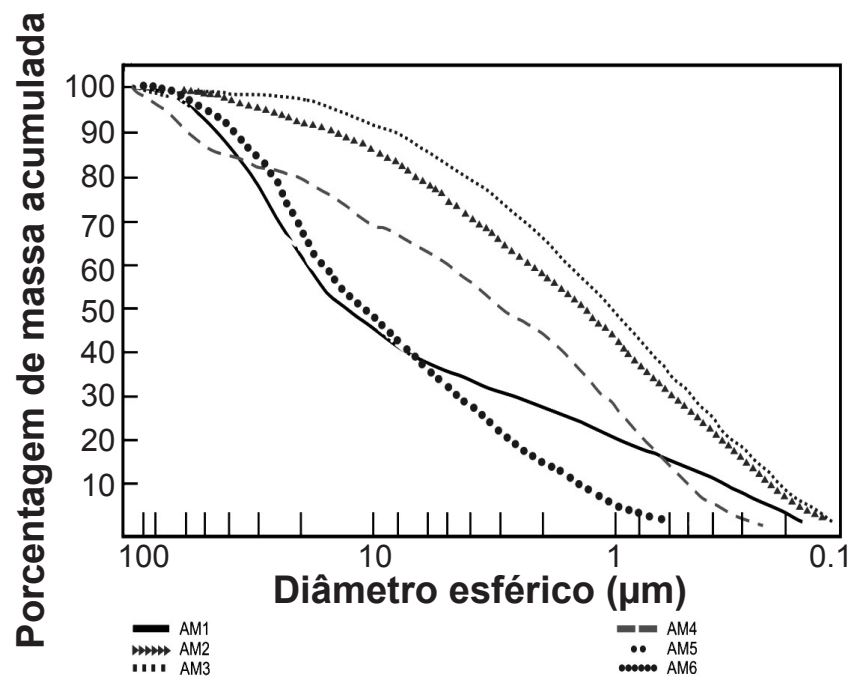

Figura 7: Porcentagem de massa acumulada versus diâmetro esférico equivalente - distribuição do tamanho de partículas. [Figure 7: Particle size distribution of the samples.]

Os resultados do ensaio de perda ao fogo estão na Fig. 8. Este ensaio consiste na determinação da perda da massa dos corpos de prova antes e depois da queima $[10,11]$.

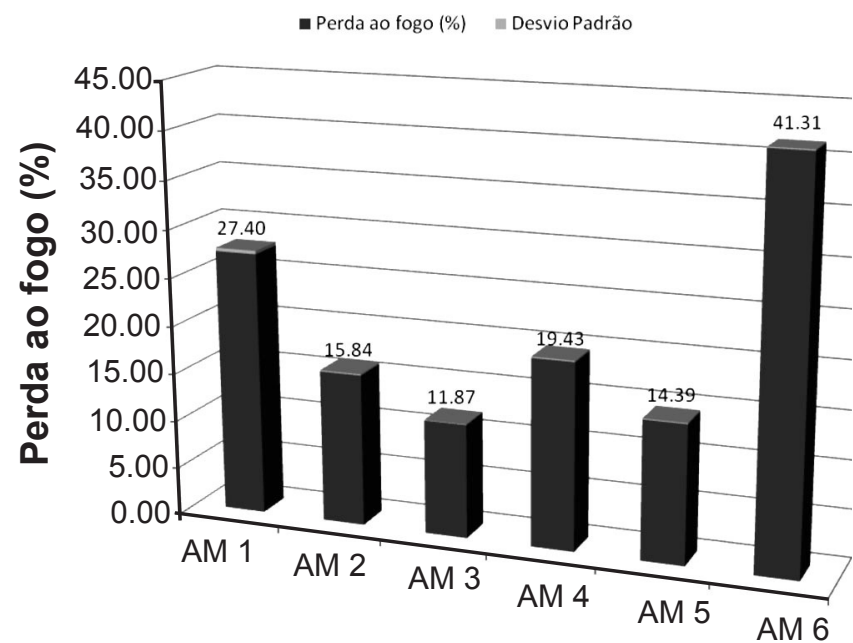

Figura 8: Perda ao fogo de cada amostra.

[Figure 8: Loss on ignition of the samples.] 
A argila AM6 foi o material que apresentou maior perda ao fogo. Esta amostra perde $\sim 41 \%$ de sua massa original durante a queima, seguida da AM1, que tem uma perda de $26 \%$, enquanto que as demais as argilas apresentam uma faixa de perda ao fogo entre $12 \%$ e $19 \%$. A argila AM6 apresenta esse valor de perda relativamente alto, por possuir bastante matéria orgânica, que é volatilizada durante a queima. A retração linear consiste na variação das dimensões lineares em porcentagem. Seu valor será positivo quando houver retração e negativo quando houver expansão [12, 13]. Matematicamente, a porcentagem de retração linear é a relação entre a diferença dos comprimentos, Lo (comprimento após a secagem) e Lf (comprimento após a queima) por Lo [14]. A amostra que apresentou menor valor de retração linear a $1000{ }^{\circ} \mathrm{C}$ foi a AM2, ou seja, sob este aspecto, esta amostra é a que tem melhor resultado de retração linear. A $1100{ }^{\circ} \mathrm{C}$ houve um incremento na retração linear de todas as amostras, o que mostra que a sinterização está progredindo. Este fato fez com que se programassem novas queimas, em temperaturas superiores, na segunda etapa de estudo. Os resultados referentes a este ensaio são apresentados graficamente nas Figs. 9 e 10.

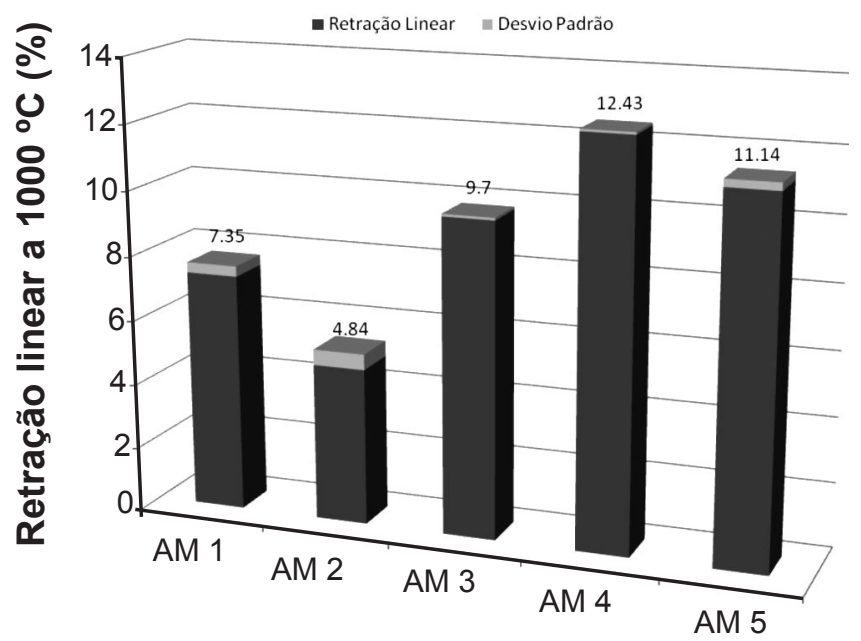

Figura 9: Retração linear das amostras a $1000^{\circ} \mathrm{C}$.

[Figure 9: Linear srinkage of the samples at $1000^{\circ} \mathrm{C}$.]

A avaliação da retração linear para amostras de argila AM6 queimadas a $1000{ }^{\circ} \mathrm{C}$ não foi realizada, em função de sua instabilidade, extremamante frágil, que se fragmenta durante a queima. Tal fato deve-se à elevada presença de voláteis, associada à baixa temperatura de queima, insuficiente para aquisição de resistência mecânica mínima $[15,16]$.

A Fig. 11 indica os resultados de densidade a verde das amostras investigadas.

Todas as amostras apresentaram densidade a verde $<1,60 \mathrm{~g} / \mathrm{cm}^{3}$. Este fato se deve à baixa plasticidade das amostras, que não promove a compactação eficiente dos grãos. A argila turfosa apresentou os mais baixos valores de densidade a verde, se comparada às demais argilas.

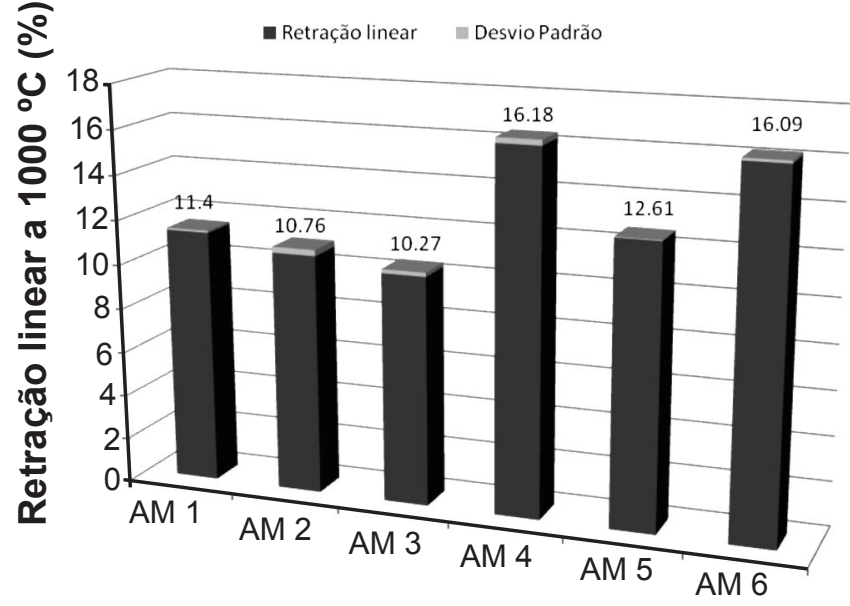

Figura 10: Retração linear de cada amostra a $1100^{\circ} \mathrm{C}$. [Figure 10: Linear srinkage of the samples at $1100{ }^{\circ} \mathrm{C}$.]

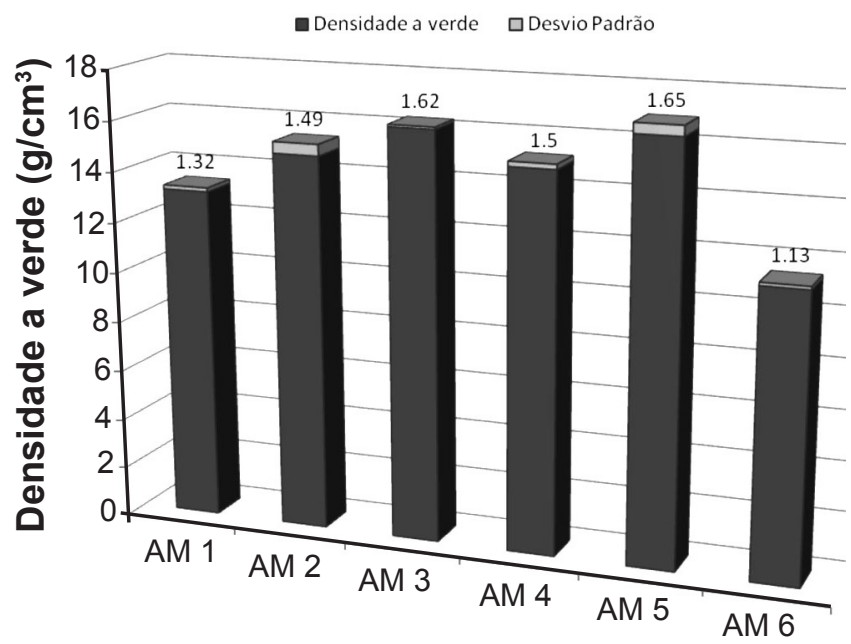

Figura 11: Densidade a verde das amostras.

[Figure 11: Green density of the samples.]

Isto se deve ao formato laminar dos agregados de matéria orgânica, que promovem a laminação dos corpos de prova, dificultando a compactação dos mesmos. Este resultado pode ser relacionado aos resultados obtidos na distribuição do tamanho de partículas (tanto via peneiramento como no sedígrafo), onde se observou que esta amostra apresenta mais de 50\% dos grãos com tamanho $>10 \mu \mathrm{m}$. As argilas

Tabela III - Índice de plasticidade das amostras investigadas. [Table III - Plasticity index $f$ the samples.]

\begin{tabular}{cc}
\hline Amostra & Índice de plasticidade \\
\hline AM1 & 5,6 \\
AM2 & 13,4 \\
AM3 & 15,0 \\
AM4 & 9,6 \\
AM5 & 12,9 \\
\hline
\end{tabular}


com maior porcentagem de grãos abaixo deste valor tiveram um incremento nos valores de densidade a verde (AM3 e AM2). A Tabela III apresenta os resultados de plasticidade obtidos a partir dos valores calculados experimentalmente de limite de plasticidade (LP) e limite de liquidez (LL). Cabe salientar que o índice de plasticidade da argila turfosa não foi obtido, já que os ensaios referentes à determinação dos valores de LP e LL se mostraram pouco reprodutíveis e, portanto, pouco confiáveis, em virtude da dificuldade de se obter os corpos de prova nas medidas exigidas por norma $[17,18]$.

Materiais que apresentam índice de plasticidade entre 1 e 7 são considerados fracamente plásticos [14]. No presente trabalho, a argila AM1 apresentou tal comportamento. Valores entre 7 e 15 indicam um material mediamente plástico. Neste caso inserem-se as argilas AM2, AM4 e AM5; a argila AM3 apresentou a maior plasticidade, com um IP igual a 15, valor este limite entre a classificação de uma argila mediamente plástica e altamente plástica. Ao analisar conjuntamente todas as propriedades verifica-se que o conjunto de amostras em estudo pode ser dividido em dois subconjuntos principais: um subconjunto em que consta a amostra AM6, não plástica, com alto teor de matéria orgânica volátil, baixa densidade a verde e um segundo agrupamento formado pelas demais amostras, em geral refratárias, de baixa plasticidade e compactação que pode ser incrementada com modificações na carga de prensagem.

\section{CONCLUSÕES}

As argilas estudadas, de um modo geral, possuem baixa plasticidade e alta refratariedade, embora a elevada área de superfície específica e distribuição de tamanho de partículas majoritariamente composta de finos favoreçam a sinterização. As amostras cuja sinterização observada foi menos eficiente foram as das argilas AM3 e AM6, em função de suas características físico-químicas. Depreendese também com os resultados de perda ao fogo que as amostras possuem uma porcentagem considerável de perda ao fogo, principalmente as argilas AM6 e AM1, indicando que estas contêm quantidades relevantes de voláteis $\left(\mathrm{H}_{2} \mathrm{O}\right.$ e $\left.\mathrm{CO}_{2}\right)$ e matéria orgânica. Todas as amostras em estudo apresentaram densidade a verde $<1,60 \mathrm{~g} / \mathrm{cm}^{3}$, o que pode ser atribuído aos baixos valores de plasticidade obtidos. Estes estudos preliminares permitiram observar que as argilas AM1 a AM5 apresentam potencial uso em refratários e formulação de porcelanatos. A partir da análise dos resultados obtidos para a amostra AM6, sugerese aplicação relacionada à correção de solos.

\section{REFERÊNCIAS}

[1] Anuário Mineral Brasileiro, DNPM 2010, MME, Brasília, Apêndice: endereço de produtores de minerais para a indústria (2010).

[2] G. M. Bustamante, J. C. Bressiani, A indústria cerâmica brasileira, Ceramic News 7, 1 (2000) 55-59.

[3] J. C. Cavalcante, H. C. Cunha, L. A. Chieregati, L. Q. Kaeffer, J. M. Rocha, E. C. Daitx, M. G. da N. Coutinho, K. Yamamoto, J. B. V. Drumond, D. B. Rosa, R. Ramalho, "Projeto Sapucaí. Estados de S. Paulo e Minas Gerais", DNPM/CPRM, Brasília, DF (1979) 299p.

[4] B. Hartmut, P. C. Jacques, The Brazilian mineral resources, Earth-Science Rev. 17, 1-2 (2009) 177-206.

[5] H. D. Schorscher, M. E. Shea, The regional geology of the Poços de Caldas alkaline complex: mineralogy and geochemistry of selected nepheline syenites and phonolites, $\mathrm{J}$. Geochem. Expl. 45, 1-3 (1992) 25-51.

[6] J. E. Burst, The application of clay minerals in ceramics, Appl. Clay Sci. 5, 5-6 (1991) 421-443.

[7] P. Souza Santos, "Ciência e Tecnologia de Argilas", Vol. 1, $2^{a}$ Ed., Edgard Blücher Ltda., S. Paulo, SP (1989).

[8] I. Valeton, A. Schullmann, R. Vinx, M. Wieneke, Supergene alteration since the upper cretaceous on alkaline igneous and metasomatic rocks of the Poços de Caldas ring complex, Minas Gerais, Brazil, Appl. Geochem. 12 (1997) 133-154.

[9] E. Facincani, "Tecnologia Cerâmica - los Ladrillos", Faenza Ed. Iberica S. L. Editora, Barcelona, Espanha (1993) p. 263.

[10] G. W. Brindley, Cerâmica 24, 102 (1978) 217.

[11] W. D. Johns, Am. Ceram. Soc. Bull. 44, 9 (1965) 682.

[12] P. S. Santos, J. Rawet, Cerâmica 26, 128 (1980) 193.

[13] C. F. Gomes, "Argilas: O que são e para que servem", Fundação Calouste Gulbenkian, Lisboa, Portugal (1986).

[14] F. Singer, S. S. Singer, Bilbao, Ediciones URMO, Ceram. Ind. 1 (1971).

[15] P. B. L. Agenor, C. P. Jordão, J. L. Pereira, C. R. Bellato, "Caracterização Química e Física de Turfa Litorânea e Avaliação da Adsorção Competitiva por Cobre e Zinco", Dep. Química, Universidade Federal de Viçosa, Viçosa, MG, Química Nova 24, 1 (2001) 18-23.

[16] V. Beltran, E. Sanchez, J. Garcia, F. Ferrando, Tile Brick Int. 12 (1996) 320.

[17] C. R. Sanchez Soto, J. L. Diaz-Hernández, M. RaigónPichardo, A. Ruíz Conde, G. Garcia-Ramos, British. Ceram. Trans. 93 (1994) 196.

[18] W. Senço, "Manual de Técnicas de Pavimentação", Vol. I, Ed. Pini, S. Paulo, SP (1997).

(Rec. 23/08/2011, Rev. 09/05/2012. 18/09/2012, Ac. $30 / 09 / 2012)$ 